\title{
Process Simulation and Cost Analysis for Removing Inorganics from Wood Chips Using Combined Mechanical and Chemical Preprocessing
}

\author{
Hongqiang Hu ${ }^{1}$ - Tyler L. Westover ${ }^{1} \cdot$ Robert Cherry $^{1} \cdot$ John E. Aston $^{1}$ • \\ Jeffrey A. Lacey ${ }^{1}$ - David N. Thompson ${ }^{1}$
}

Published online: 3 October 2016

(C) The Author(s) 2016. This article is published with open access at Springerlink.com

\begin{abstract}
Inorganic species (ash) in biomass feedstocks negatively impact thermochemical and biochemical energy conversion processes. In this work, a process simulation model is developed to model the reduction in ash content of loblolly logging residues using a combination of air classification and dilute-acid leaching. Various scenarios are considered, and it is found that costs associated with discarding high-ash material from air classification are substantial. The costs of material loss can be reduced by chemical leaching the high-ash fraction obtained from air classification. The optimal leaching condition is found to be approximately $0.1 \mathrm{wt} \%$ sulfuric acid at $24{ }^{\circ} \mathrm{C}$. In example scenarios, total process costs in the range of $\$ 6-9 /$ dry tons of product are projected that result in a removal of $14,62,39$, and $88 \%$ of organics, total ash (inorganics), alkaline earth metals and phosphorus (AAEMS + P), and silicon, respectively. Sensitivity analyses indicate that costs associated with loss of organic material during processing (yield losses), brine disposal, and labor have the greatest potential to impact the total processing cost.
\end{abstract}

Keywords Biofuels $\cdot$ Air classification $\cdot$ Leaching $\cdot$ Ash reduction $\cdot$ Technoeconomic analysis

Electronic supplementary material The online version of this article (doi:10.1007/s12155-016-9794-3) contains supplementary material, which is available to authorized users.

Tyler L. Westover tyler.westover@inl.gov

1 Idaho National Laboratory, 2525 Fremont Ave, Idaho Falls, ID 83415, USA

\section{Introduction}

Lignocellulosic biomass from agricultural residues, forest residues, urban wastes, and dedicated energy crops are recognized as renewable and sustainable energy sources that can be converted to liquid fuels, heat, and power through biological, chemical, and thermal conversion processes [1, 2]. Approximately 500 million dry tons of residues and energy crops are available annually in the USA, and this quantity could increase to more than a billion dry tons by 2030 [3]. Inorganic species, whether physiological or exogenously introduced, are a notable component of biomass resources and are often referred to as ash. Thermochemical and biochemical conversions can both be affected by ash, although differently. During fast pyrolysis, alkali metals and alkaline earth metals catalyze the degradation of biomass to gaseous products and decrease oil yields. Several studies have correlated increasing content of alkali and alkaline earth metals (AAEMs), including potassium, sodium, calcium, and magnesium, with decreasing oil yield [4-6]. Inorganic species can also poison or foul catalysts that promote the conversion of biological carbon to oil and also promote coagulation of final fuel products and plugging of fuel lines if they are not removed. In addition, at the higher temperatures of gasification and combustion, alkali and silicon (in the form of silica) contribute to fouling and scaling of reactor surfaces and heat transfer tubes, leading to diminished overall thermal efficiency [7]. Combusting biomass with high levels of sulfur, nitrogen, chlorine, or heavy metals can create hazardous air pollutants in the form of sulfur and nitrogen oxides, hydrogen chloride, dioxins, furans, heavy metals, and particulate emissions [8]. In biochemical processes, Weiss et al. [9] found that increasing ash content was correlated to increased buffer capacity and decreased pretreatment yields. The results further indicated that the acid-neutralizing compounds were primarily from soil contamination and not from physiological-bound ash in the vascular structure. Inorganic elements that are typically considered physiologically bound with 
the organic material are those that are common in biological processes and include $\mathrm{Ca}, \mathrm{K}, \mathrm{Mg}, \mathrm{S}, \mathrm{Mn}$, and P [10]. However, ash from either source, physiological or exogenous, is expected to increase water treatment cost and may be solubilized during biochemical pretreatment, resulting in inorganic contaminants in the intermediate products. In each of these biofuels conversions, there is a consequent economic incentive to use biomass with lower ash content.

A variety of mechanical, aerodynamic, and chemical leaching methods have been applied to remove unwanted ash species while minimizing the loss of organic material, including sieving, air classification, water washing, and wet chemical leaching. The work presented here focuses on air classification, water washing, and wet chemical leaching. Sieving is based exclusively upon particle size and shape and takes advantage of the fact that different fractions of the biomass - for instance bark, seeds, or white wood - will tend to break into different-sized pieces during size reduction, providing a basis for separation. Because the different anatomical fractions have different ash contents and compositions, selective ash separation is possible. In addition to separating anatomical fractions, sieve separation also has potential to remove fine soil particles adhering to biomass by vibration and the use of sieves with small openings can allow small soil particles to pass through while capturing larger organic particles. Liu and Bi [11] demonstrated that sieving could remove $33 \%$ of the total ash from pine bark while only removing $24 \%$ of the organic material. The results for switchgrass were approximately half that of pine bark: removing $16 \%$ of the total ash also removed $11 \%$ of the organic material.

Air classification is another dry separation method that is recognized as an effective separation technology in a wide variety of industries [12]. Similar to sieving, it operates on particle size and shape; however, air classification is also affected by particle density. Air classifiers work by blowing a stream of air through a loose flow of biomass particles. Particles that are lighter or have more aerodynamic drag will be entrained in the air stream and carried to a different discharge point than the main mass of particles. Smaller particles, even with the same shape and density as the larger ones, will also separate because of their higher ratios of cross-sectional area to weight. Similar to sieving, air classification potentially separates inorganic dust and different biomass anatomical fractions from each other to isolate fractions with different organic and inorganic chemical compositions. Lacey et al. [10] demonstrated that a combination of sieving and air classification could remove $49 \%$ of total ash from forest residues while only removing $7 \%$ of the organic material.

Water washing, either by rainfall in the field or through laboratory grinding, soaking, and dewatering processes, has been shown to be effective for reducing inorganic content [7, 13, 14]. Rain washing has advantages of being inexpensive and returning nutrients back to the soil but is subject to weather variability and organic degradation. In laboratory settings, water washing can be carried out by cold or hot water via spraying, flushing, or soaking. Soaking was reported as being more effective than spraying and flushing, as was hot water treatment compared to cold water processes [15]. Similarly, room-temperature washing has been shown to remove approximately $80 \%$ of alkali metals from switchgrass [4] and banagrass [16]. Said et al. [17] reported that washing removed as much as $87,60,50$, and $39 \%$ of $\mathrm{Cl}, \mathrm{Na}, \mathrm{K}$, and $\mathrm{Mg}$, respectively, from various rice straws.

As described below, removal of greater amounts of inorganics, especially water-insoluble inorganics, can be achieved by leaching with dilute acid catalyst and perhaps at hotter temperatures $[4,18]$, although leaching with acid catalysts leads to additional wastewater treatment and perhaps fertilizer costs because the leaching solution cannot be directly returned to the field at low $\mathrm{pH}$. Mourant et al. [19] reported that hot, deionized water was effective for removing $\mathrm{Na}, \mathrm{K}$, and $\mathrm{Mg}$. As treatment severity increases, more inorganics can be removed; however, the organic material is also affected. Scott et al. [20] demonstrated that $0.1 \mathrm{wt} \% \mathrm{HNO}_{3}$ at $30{ }^{\circ} \mathrm{C}$ removed the majority of alkaline ions; however, the reaction removed hemicellulose and reduced the degree of polymerization (DP) of cellulose. Using a higher acid concentration of $2 \mathrm{wt} \% \mathrm{H}_{3} \mathrm{PO}_{4}$ at room temperature, Dobele et al. [21] removed a large fraction of inorganics but most of the levoglucosan produced in subsequent pyrolysis was converted to levoglucosone, a less desirable intermediate product. Liu and $\mathrm{Bi}$ [11] compared the leaching results of hydrochloric, acetic, and nitric acids to remove inorganics from pine bark and removed $100,98,92$, and $90 \%$ of $\mathrm{Na}, \mathrm{Mg}, \mathrm{K}$, and $\mathrm{Ca}$, respectively. Nitric acid removed the most inorganics at the lowest concentration; however, acetic acid removed the most inorganics at the same $\mathrm{pH}$ level. Reza et al. [22] reported removal of inorganics from corn stover using formic, oxalic, tartaric, and citric acids, finding that the $5 \%$ sodium citrate at $130{ }^{\circ} \mathrm{C}$ and 2.7 bar removed $86 \%$ of combined $\mathrm{Na}, \mathrm{Mg}, \mathrm{K}$, and $\mathrm{Ca}$ because of its chelating properties.

Each method has advantages and disadvantages; however, estimated equipment and operating costs have rarely been reported for processes to remove inorganics from raw biomass materials, especially using combined mechanical and wet chemical methods. This work fills that need by providing a process simulation model using Aspen Plus ${ }^{\circledR}$ (Aspentech, Bedford, MA, USA), including estimated costs and performances, of combining the air classification processes described by Lacey et al. [10] with dilute sulfuric acid leaching experiments conducted at Idaho National Laboratory (INL) [unpublished results]. The material considered is loblolly pine residues, and the processes include air classification after chopping to bulk chips, and then leaching of different airclassified fractions at three different conditions: (1) a simple water wash at ambient temperature $\left(24^{\circ} \mathrm{C}\right)$, (2) leaching using $0.1 \mathrm{wt} \% \mathrm{H}_{2} \mathrm{SO}_{4}$ at ambient temperature, and (3) leaching 
using $1.0 \mathrm{wt} \% \mathrm{H}_{2} \mathrm{SO}_{4}$ heated to $90{ }^{\circ} \mathrm{C}$. Process energy consumption, energy recovery, and processing costs (capital and operation) are analyzed and reported.

\section{Materials and Methods}

\section{Process Overview and Material Description}

The process simulation includes air classification, leaching, and subsequent drying of leached wood chips to prepare them for long-term storage. Chopping operations and drying operations before the air classifier and leacher are not included in the process simulation or estimated economics because those costs are already accounted for in logistics design cases for woody feedstocks [23]. Material coming into the process is assumed to be loblolly logging residues, chipped to widths of $5.8 \mathrm{~cm}$ and thicknesses of approximately of $0.4 \mathrm{~cm}$ and dried to $8-12 \%$ moisture at a flow rate of 22.68 dry tons $(\mathrm{dt})$ of wood per hour as described in [10] $(1 t=1000 \mathrm{~kg})$. The logging residues were supplied by Verdante Bioenergy Services, LLC from near Raleigh, NC. The total ash content of the wood chips is assumed to be $1.11 \mathrm{wt} \%$ (dry basis). Only the major components of the ash are considered in this simulation, which is assumed to consist of $\mathrm{Si}$ and carbonate salts of $\mathrm{Ca}, \mathrm{K}, \mathrm{Mg}, \mathrm{Na}$, and $\mathrm{P}$ (AAEMS + P) at 45, 13.4, 12.2, 5.3, 1.5, and $2.7 \mathrm{wt} \%$, respectively [10].

\section{Air Classification}

The wood chips are first air classified in either one or two steps with potentially different air flow speeds to generate two or three product streams that may be discarded, leached, or accepted as on-spec feedstock without further treatment. The air classification cost modeling is based upon a $2 \times$ Air Cleaner (Key Technology, Walla Walla, WA) that is a freestanding machine supplied fully assembled and equipped with an Iso-flo dewatering infeed shaker. Previous experiments optimized the fan speeds to separate fractions of chipped pine residues for disposal and leaching [10]. Fan speeds are set using a variable frequency drive (VFD) that offers control from 10 to $60 \mathrm{~Hz}$, although the maximum frequency used in the simulation was $40 \mathrm{~Hz}$. The capital and operating costs of the air classifier are estimated below in the economic analysis section. After air classification, retained particles are further size reduced to a particle size of $0.6 \mathrm{~cm}$. As noted above, costs associated with grinding operations are not included in this effort because they are already accounted for in current logistics design cases for woody feedstocks [23]. The assumed process scale of $22.68 \mathrm{dt} / \mathrm{h}$ is equivalent to $178,809 \mathrm{dt} /$ year at $90 \%$ operation capacity and is consistent with the expected scale of a biomass depot [23].

\section{Chemical Leaching}

After air classification and potentially additional grinding, a fraction of the wood chips are leached. Leaching experiments using loblolly logging residue wood chips have been conducted at various levels of sulfuric acid concentration, temperatures, and leaching times (Idaho National Laboratory, unpublished results). Among the various inorganic species, special consideration was given to alkali and alkaline earth metals (AAEMs $=\mathrm{Ca}+\mathrm{K}+\mathrm{Mg}+\mathrm{Na}$ ) due to their dominance in biomass ash content and their negative effects on thermochemical conversions [24]. The total removal of these four elements at various conditions is depicted in Supplementary Fig. 1 and indicate that leaching with $0.1 \%$ acid at $24{ }^{\circ} \mathrm{C}$ is the least severe condition that results in the removal of nearly $90 \%$ of AAEMs.

Within the simulation framework, the removal of inorganics is simulated using diffusion kinetics of the respective ions, and data from experiments (Supplementary Fig. 1) was used to validate the simulated process, which is shown in Supplementary Fig. 2. The MIXCINC module within Aspen Plus was selected for stream class to handle mixed solid streams containing inert and nonconventional materials. The electrolyte non-random two-liquid model using the Redlich-Kwong equation of state and Henry's law (ENRTL-RK) was selected as the property methods to accommodate an asymmetric reference state for ionic species. Enthalpy and density of the wood particles were defined using non-conventional material properties. Calculators using FORTRAN programs were defined as needed using flow sheet options to determine desired inputs or outputs for various block operations. Wood chips enter the process at the top left in the stream as RAWWOOD1 at a flow of $22.68 \mathrm{dt} / \mathrm{h}$. Air classification and a potential grinding operation to reduce the chips to $6 \mathrm{~mm}$ size for leaching is included in the diagram but not actually modeled in Aspen Plus. After air classification and grinding, the first operation SALT-SET is not an actual piece of equipment but is simply the mechanism used within the simulation software to specify the content of inorganic species in the material fractions coming from the air classification operation. Next, the wood chips move to a degassing pot that removes air presumed to be entrained with the wood. This step has little function in the simulation but is necessary in real applications.

The leacher is modeled as a five-stage counter-current extraction. However, the actual mechanical configuration might be as simple as five tanks with water pumped between them. Within each stage of the leacher, an arbitrarily large water-tosolids ratio can be recirculated without affecting the material balance. The rinse water feed is heated to the leaching temperature before entering the leacher. For acid leaching, stages 1 to 3 include acid catalyst, while stages 4 and 5 rinse the wood chips with clear water. The acid concentration was set at $1.0 \mathrm{~g}$ acid per $\mathrm{kg}$ dry wood $(0.1 \mathrm{wt} \%)$, resulting in a $\mathrm{pH}$ of approximately 3 for effective extraction of inorganics [25], 
although other scenarios using water with 0.0 and $1.0 \mathrm{wt} \%$ acid were also considered. In another scenario, hot, saltcontaining water leaves the leacher and is pumped to an evaporator where steam heat boils off about one third of the water to reduce the volume of brine to be disposed. The heat in that vaporized water is used to preheat the evaporator feed, to add heat to the leacher to compensate for wood and sulfuric acid streams that enter the leacher at room temperature, and to preheat the leacher rinse water. The arrows on heat streams in Supplementary Fig. 2 show the direction of information flow in the simulation, which is opposite the direction of heat flow. The majority of remaining vaporized water is condensed using cooling water. Any non-condensable gas present in the cooling water is vented from that exchanger. The clean condensed water is recycled to the rinse water fed to the leacher. After being discharged from the leacher, the de-ashed biomass enters a drainer. The water from that step is recycled to the leacher even though it contains a small content of leached salts. The wet biomass flows to a dryer, considered to be a natural gas-fired, direct contact rotary dryer. In order to achieve a stream of reduced-ash biomass with 8-12\% moisture content suitable for long-term storage, a design specification was applied in this block to calculate the air flow rate, which was determined to be $6280 \mathrm{~kg} / \mathrm{h}$. Evaporated water is vented to the atmosphere but could be condensed and recycled.

The simulation employs stoichiometric reactions to convert the carbonate salts $\left(\mathrm{CaCO}_{3}, \mathrm{Na}_{2} \mathrm{CO}_{3}, \mathrm{MgCO}_{3}, \mathrm{~K}_{2} \mathrm{CO}_{3}\right)$ to conventional inert solutes dissolved in aqueous solution. The conversion fractions were the leaching extents of carbonate salts from wood chips at a specific residence time defined as calculated using the flat slab diffusion kinetics model described in the Supplementary Material. Importantly, there is a non-leachable fraction for each ion that cannot be removed even for very long residence times, the exact quantity of which depends upon process temperature and $\mathrm{pH}$. For logging residue pine wood chips considered in this work, the nonleachable fractions for $\mathrm{Ca}, \mathrm{Mg}, \mathrm{Na}$, and $\mathrm{K}$ are approximately $12,12,30$, and $8 \%$, respectively at $0.1 \mathrm{wt} \%$ sulfuric acid $\left(\mathrm{H}_{2} \mathrm{SO}_{4}\right)$ addition, and they are temperature independent in the range $20-90{ }^{\circ} \mathrm{C}$ (Idaho National Laboratory, unpublished results). For 4-h residence time, the leaching extents for $\mathrm{Ca}$, $\mathrm{Mg}, \mathrm{Na}$, and $\mathrm{K}$ are $80.4,80.4,64$, and $84.1 \%$, respectively, which correspond to an overall ash removal of approximately $80 \%$.

Although the process design presented here appears adequate, it may not be fully optimized. Several opportunities exist for further optimization, particularly with regard to the operation of the leacher. First, greater acid content of the leaching liquor provides more complete leaching of the ash elements, but acid must be purchased on a continuing basis, and an alkaline-neutralizing agent, such as sodium carbonate, may be needed as well to bring the discharge stream $\mathrm{pH}$ closer to neutral as part of the treatment process before the salts can be removed and the water reused in the leacher. In addition, use of acid solutions requires equipment made of higher-cost materials that can tolerate increased acid levels. Second, increasing the size of the leacher increases the residence time of material in the leaching process to potentially remove more inorganic material; however, increasing the size of the leacher also increases capital and operating costs. Third, the temperature of leaching is another tradeoff between increased loss of organics from the biomass at higher temperatures and not having a productive use for heat recovered from the evaporator overhead stream. As discussed above, temperature can also affect the rate of diffusion because diffusivity in liquid phase is proportional to absolute temperature [26]. Raising the leaching temperature from 24 to $90{ }^{\circ} \mathrm{C}$ represents a modest $22 \%$ increase in absolute temperature and therefore diffusion rate. A second way in which increasing the temperature may prove beneficial is in increasing the solubility of lowsolubility species. Higher solubility increases the concentration of inorganic species in the biomass pores, which then accelerates diffusion out of the biomass because of the increased concentration gradient. Resolving the optimum leaching temperature thus includes assessing the relative costs of leacher size and brine disposal, including evaporation to reduce the brine volume.

\section{Economic Analysis}

\section{Approach and Assumptions}

Capital and operating costs were analyzed following assumptions consistent with the US Department of Energy's Bioenergy Technology Office's (BETO's) 2017 fast pyrolysis and upgrading design case [1], except for the assumed construction period. In this work, the construction period is assumed to be less than 1 year instead of 3 years because the facility is much smaller and simpler. Major cost assumptions are summarized in Table 1. All costs presented are on a 2011 constant US dollar basis. Indices used to convert capital and operating costs to the 2011 US dollars can be found in [1]. Capital costs are estimated from a variety of resources but use vendor quotes if available. Individual installation factors for equipment are calculated by Aspen Capital Cost Estimator. The total direct cost is the sum of all the installed equipment costs, plus the costs for land, buildings, additional piping, and site development (calculated as $1,4,4.5$, and $10 \%$ of purchased equipment, respectively). Indirect costs are estimated as $60 \%$ of the total installed costs. The sum of the direct and indirect costs is the fixed capital investment (FCI). Total capital investment (TCI) is the sum of the FCI and working capital ( $5 \%$ of FCI). The operations considered in this work are assumed to be performed at a functioning biomass 
Table 1 Cost assumptions for air classification and chemical leaching (consistent with [1])

\begin{tabular}{ll}
\hline Assumption description & Assumed value \\
\hline Plant life & 30 years \\
Plant financing debt/equity & $60 \% / 40 \%$ of total capital investment \\
Interest rate for debt financing & $8.0 \%$ \\
Term for debt financing & 10 years \\
Construction period & 1 year \\
On-stream factor & $90 \%$ (7884 operating hours per year) \\
Shift supervisor/operator salary & $\$ 52,700$ per year \\
Benefits and general overhead & $90 \%$ of total salaries \\
Maintenance & $3 \%$ of fixed capital investment \\
Insurance and taxes & $0.7 \%$ of fixed capital investment \\
\hline
\end{tabular}

preprocessing depot, such that process costs are considered as incremental costs for adding operations. For example, the incremental increase in the number of operating laborers $\left(N_{I N C-}\right.$ $O L$ ) is estimated using

$N_{\text {INC-OL }}=\left(6.29+0.23 N_{\text {new-op }}\right)^{0.5}-\left(6.29+0.23 N_{\text {prev-op }}\right)^{0.5}$

where $N_{\text {new-op }}$ is the total number of operating steps including the new operations and the $N_{\text {prev-op }}$ is the total number of operating steps before the new operations are added [27]. The formula above indicates that the labor needed to add a single operation is $4.2 \%$ of operation time, and this value is insensitive to the value of $N_{\text {prev-op }}$. The depot is assumed to operate on a shift-work basis with five shifts that operate $8 \mathrm{~h}$ each, such that adding an operation requires the equivalent of $5 \times 4.2 \% \approx 21 \%$ of an operator shift.

\section{Air Classification Cost Estimate}

Approximate costs associated with air classification have been estimated previously [10] using the Lang Factor method, which has a tendency to produce high results. Here, we report a more detailed cost analysis consistent with [1]. As explained above, air classification is performed using equipment offered by Key Technology (Walla Walla, WA). The largest unit, model no. 16, is rated to process approximately $40 \mathrm{~m}^{3}$ of solids per hour. Assuming a dry bulk density of $200 \mathrm{~kg} / \mathrm{m}^{3}$, this is equivalent to $8.16 \mathrm{dt} / \mathrm{h}$ of wood chips, such that three machines are needed to provide the simulated $22.68 \mathrm{dt} / \mathrm{h}$ capacity. The quoted price per machine was $\$ 56,440$. Feed and product hoppers and a conveying system between them and the classifier will be needed, and these items are assumed to be of similar complexity and cost as the classifiers. The total purchase cost of three classifier trains is then approximately
$\$ 339,000$. The total installed equipment cost was estimated as $\$ 484,255$ using an installation factor of 1.43 . The number of operators is estimated using Eq. (1) and considering that a typical depot already performs five primary operations (material receiving, grinding, drying, fine grinding, and shipping) and that three new operations are added (one for each air classification train), such that $\approx 62 \%$ of a full-time operator $(24.7 \mathrm{~h} /$ week) is needed to operate the air classifier trains. We further note that the authors have experience operating an air classifier from Key Technology, and this level of operator involvement is commensurate with our experience. Table 2 shows the breakdown of estimated air classification process costs, including capital and operating costs (electricity and maintenance) and indicates that the total process cost is approximately $\$ 0.83 / \mathrm{dt}$. Again, we emphasize that this cost is the estimated incremental cost of including air classification at an operating biomass preprocessing depot and does not include the logistics costs associated with unloading material from trucks or other sources or preparing material for shipping via truck or rail because those costs are accounted for elsewhere in BETO's design cases [1,23].

Table 3 summarizes the effectiveness of the air classification process at generating fractions of forest residue wood chips with high ash content, as previously reported [10] as a function of variable frequency drive (VFD), which is used to control the fan velocity. Using only a vibrating screen, $18 \%$ of the initial inorganic material was removed in a fraction that contained only $2 \%$ of the initial organic material. Increasing the fan speed increases the amounts of both organic and inorganic materials that were separated from the initial material. A VFD setting of $12 \mathrm{~Hz}$ removed nearly half of the initial inorganic material while removing less than $10 \%$ of the organic material [10]. As discussed above, separated fractions that contain a high concentration of inorganic material can be leached and returned to the biomass product stream or they can be discarded or used in another process that is less sensitive to inorganic species. For example, the separated fraction may be used as fuel or in a biochemical conversion process to partially or fully recover the cost of the material. In order to estimate the cost associated with repurposing high ash fractions, we consider burning the separated fraction as fuel as an example.

The cost of biomass feedstock varies with the demand. The Billion Ton Update projects that as much as 182 million dry tons (dt) of biofuel resources may be available in 2022 for a mean price of approximately $\$ 66 / \mathrm{dt}$ [33]. The value of biomass as fuel depends upon its energy content, handling costs, and ash disposal costs. Assuming a lower heating value of $14.6 \mathrm{GJ} / \mathrm{dt}(7000$ BTU/lb) for wood chips and a fuel value of $\$ 3.17 / \mathrm{GJ}$ (\$3.00/MMBTU, which is less than natural gas to reflect transport, handling, and ash disposal costs), the fuel value of separated wood fractions with relatively high inorganic content is approximately $\$ 46.30 / \mathrm{dt}$, such that the unit 
Table 2 Process costs for air classification at $22.68 \mathrm{dt} / \mathrm{h}$ of wood chips

\begin{tabular}{llll}
\hline Cost component & Usage & Unit cost & Cost $(\$ / \mathrm{dt})$ \\
\hline Installed equipment cost & $100 \%$ & $\$ 484,000$ & \\
Fixed capital investment & $100 \%$ & $\$ 841,000$ & \\
Total capital investment & $100 \%$ & $\$ 1,124,000$ & 0.21 \\
Salaries & $62 \%$ & $\$ 52,700 / \mathrm{year}$ & 0.18 \\
Electricity for blowers & $2 @ 15 \mathrm{HP}$ & $\$ 0.10 / \mathrm{kWh}$ & 0.10 \\
Other fixed costs & $100 \%$ & $\$ 55,000 / \mathrm{yr}$ & 0.34 \\
TOTAL & & & 0.83 \\
\hline
\end{tabular}

Process costs are defined as the sum of capital and operating costs, excluding the impact of feedstock costs or costs due to loss of material [1].

yield loss is approximately $\$ 66 / \mathrm{dt}-\$ 46.3 / \mathrm{dt} \approx \$ 20 / \mathrm{dt}$. An additional consideration is that high-ash fractions that are separated by air classification at low fan speeds may be undesirable for conversion due to chemical composition other than inorganic content. For example, the material collected with the VFD set to $10 \mathrm{~Hz}$ consists primarily of dust and thin pieces of bark and wood but no needles [10]. The needles were found almost exclusively in the light fractions collected with the VFD in the range 12$15 \mathrm{~Hz}$. Considering all of the many factors that affect the actual financial loss associated with discarding or repurposing light fractions from air classification is beyond the scope of this work; consequently, the value of $\$ 20 / \mathrm{dt}$ is chosen as a reasonable and convenient value that makes it possible to approximately compare capital and operating costs with costs associated with losses of organic material. As shown in Table 3, for simple screen separation $(\leq$ Screen), the process cost is greater than the yield loss cost; however, using a fan to air classify the material increases the loss of organic material, such that those losses quickly surpass and dominate over process costs as fan speed increases.

\section{Leaching Capital Cost Estimate and Capital Charge}

Based on the process flow diagram in Supplementary Fig. 2, capital and operating costs for the biomass leaching were estimated by Aspen Process Economic Analyzer (Version 8.6). Each unit on the flow sheet was mapped to one or more standard equipment items included in a built-in capital cost database. The Aspen Economic Analyzer adjusts the built-in estimate to match the capacity needed in the flow sheet. However, not all types and sizes of equipment are included in that database, so it is sometimes necessary to use a mapping to equipment of similar but not identical function and complexity. This was necessary in several places on this flow sheet, notably the two largest equipment items, the leacher and the dryer.

Table 4 summarizes the capital costs for the leaching process and indicates that the total purchased equipment cost is approximately $\$ 680,000$ and $\$ 773,000$ with and without an evaporator, respectively. Notably, the leacher represents approximately $78 \%$ of the total equipment cost. A total residence time of $4 \mathrm{~h}$ in the first two leaching tanks was applied in this study. The residence time in the leaching tanks may not be the same for all particles due to non-uniform mixing and settling. Consequently, a third leaching tank ensures that practically all particles experience a leaching residence time equal to or greater than $4 \mathrm{~h}$. Mixing of the acid concentrate with water is assumed to occur at pipe T-junctions with negligible equipment cost. Also, for options involving water washing or acid leaching with lower acid concentration and ambient temperature, the evaporator and related heaters are unnecessary and were omitted to reduce cost. The total installed equipment cost including an evaporator was estimated as $\$ 2,111,000$ using the installation factors listed in Table 4.

The total capital investments, including loan interest for leaching without and with evaporation, are estimated to be $\$ 4.3$ and $\$ 4.7$ million dollars, respectively. Spread over a 30 -year throughput of biomass at $90 \%$ stream factor (7884 $\mathrm{h} /$ year of operation) and including other cost factors
Table 3 Effectiveness and costs of air classifying logging residue wood chips at $22.68 \mathrm{dt} / \mathrm{h}$

\begin{tabular}{llllllll}
\hline $\begin{array}{l}\text { Fan } \\
\text { speed }\end{array}$ & $\begin{array}{l}\text { Total } \\
\text { mass } \\
(\%)\end{array}$ & $\begin{array}{l}\text { Organic } \\
\text { loss }(\%)\end{array}$ & $\begin{array}{l}\text { Organic } \\
\text { loss }(\mathrm{dt})\end{array}$ & $\begin{array}{l}\text { Yield loss } \\
\text { cost }\left(\$ / \mathrm{dt}^{\mathrm{a}}\right)\end{array}$ & $\begin{array}{l}\text { Inorganic } \\
\text { removal }(\%)\end{array}$ & $\begin{array}{l}\text { AAEMS + P } \\
\text { removal }\end{array}$ & $\begin{array}{l}\text { Total cost } \\
\left(\$ / \mathrm{dt}^{*}\right)\end{array}$ \\
\hline$\leq \mathrm{Screen}$ & $2.2 \%$ & $2.0 \%$ & 0.46 & $\$ 0.41$ & $18 \%$ & $7 \%$ & $\$ 1.24$ \\
$10 \mathrm{~Hz}$ & $6.7 \%$ & $6.3 \%$ & 1.42 & $\$ 1.34$ & $42 \%$ & $17 \%$ & $\$ 2.17$ \\
$12 \mathrm{~Hz}$ & 9.1 & $8.7 \%$ & 1.97 & $\$ 1.90$ & $49 \%$ & $22 \%$ & $\$ 2.73$ \\
$15 \mathrm{~Hz}$ & 13 & $12 \%$ & 2.81 & $\$ 2.82$ & $56 \%$ & $28 \%$ & $\$ 3.65$ \\
$18 \mathrm{~Hz}$ & 17 & $17 \%$ & 3.77 & $\$ 3.99$ & $60 \%$ & $33 \%$ & $\$ 4.82$ \\
$22 \mathrm{~Hz}$ & 25 & $25 \%$ & 5.62 & $\$ 6.59$ & $65 \%$ & $41 \%$ & $\$ 7.42$ \\
\hline
\end{tabular}

Cost associated with yield loss is assumed to be $\$ 20 / \mathrm{dt}$ of lost organic material. Total cost is the sum of yield loss cost and process cost (Table 2). Adapted from [10]

${ }^{\text {a }}$ Basis is dry product. For example, $0.46 \mathrm{dt} . \$ 20 / \mathrm{dt} /(22.68 \mathrm{dt}-0.46 \mathrm{dt})=\$ 0.41 / \mathrm{dt}$ 
Table 4 Capital cost for chemical leaching process at $22.68 \mathrm{dt} / \mathrm{h}$

\begin{tabular}{lllll}
\hline Equipment & $\begin{array}{l}\text { Unit cost } \\
\text { W/ evaporator }\end{array}$ & $\begin{array}{l}\text { Unit cost } \\
\text { W/o evaporator }\end{array}$ & $\begin{array}{l}\text { Installation } \\
\text { Factor }\end{array}$ & $\begin{array}{l}\text { Size }\left(\mathrm{m}^{3}\right) \\
\text { Factor }\end{array}$ \\
\hline DEGASSER-flash vessel & $\$ 5000$ & $\$ 5000$ & 1.7 & 3 \\
LEACHER $\times 5$ & $\$ 121,000 \times 5$ & $\$ 121,000 \times 5$ & 3.0 & 156 ea. \\
EVAPORTR-flash vessel & $\$ 22,000$ & $\$ 0$ & 2.5 & 7 \\
DRAINER & $\$ 25,000$ & $\$ 25,000$ & 1.4 & 12 \\
DRYER-flash vessel & $\$ 25,000$ & $\$ 25,000$ & 1.6 & 12 \\
BRINEPMP & $\$ 6000$ & $\$ 0$ & 3.0 & 3.0 \\
BRINEHTR & $\$ 13,000$ & $\$ 0$ & 1.4 & 1.4 \\
CONDNSRx4 & $\$ 52,000$ & $\$ 0$ & 1.4 & \\
RINSEPMP & $\$ 7000$ & $\$ 7000$ & \\
RINSEHTR & $\$ 13,000$ & $\$ 13,000$ & \\
Purchased equipment cost & $\$ 773,000$ & $\$ 680,000$ & \\
Installed equipment cost & $\$ 2,111,000$ & $\$ 1,926,000$ & \\
Fixed capital investment & $\$ 3,529,000$ & $\$ 3,215,000$ & \\
Total capital investment w/o interest & $\$ 3,704,000$ & $\$ 3,375,000$ & \\
Total capital investment w/interest & $\$ 4,717,000$ & $\$ 4,298,000$ & \\
Capital cost per dt & $\$ 0.88 / \mathrm{dt}$ & $\$ 0.80 / \mathrm{dt}$ & \\
\hline
\end{tabular}

summarized in Table 1, this amounts to $\$ 0.80 / \mathrm{dt}$ and $\$ 0.88 / \mathrm{dt}$ of biomass processed without and with evaporator, respectively. Cost estimates can be scaled to other capacities using the six-tenths factor rule [28] in which the cost of equipment scales to the 0.6 power of the capacity if the plant equipment is made larger rather than duplicated at the original scale to obtain more throughput: cost of larger system $=$ (original cost) $\times(\text { larger capacity/original capacity })^{0.6}$. Hence, the current estimate of $\$ 4.3$ million for a plant of $22.68 \mathrm{dt} / \mathrm{h}$ production can be scaled to other sizes as indicated in Supplementary Table 2 .

\section{Leaching Operating Cost}

There are several components of the operating cost. The primary costs of the leaching process are labor, energy, sulfuric acid, brine disposal (which includes the extracted inorganics as well as added acid and neutralizing agents), maintenance, and operating labor. As with air classification, feedstock costs are considered separately. These are estimated in Table 5 for three different leaching options. Usage rates were taken from the flow sheet of Supplementary Fig. 2 or interpolated as explained below. Power costs for pumping included five additional pumps of $10 \mathrm{HP}$ each to recirculate leach liquor in the stages of the leacher. Energy costs reflect heat usage in the evaporator and product dryer, the first as steam assumed to be available at the site and the dryer using natural gas in a directcontact dryer using hot exhaust gas from a burner. As mentioned above, three separate options are considered.

Option 1 utilizes simple water washing at ambient temperature to minimize the process costs as much as possible and does not require further discussion, other than that the number of leachers could likely be reduced from five to three to reduce capital costs. Option 2 applies 0.1 wt $\%$ sulfuric acid at ambient temperature $\left(24{ }^{\circ} \mathrm{C}\right)$ and incurs significant brine disposal costs. The concentration of various ions in the effluent exiting the leacher (SALTWTR1 stream in Supplementary Fig. 2) were simulated as $30,383,277,80,990$, and $1330 \mathrm{mg} / \mathrm{L}$ for ions $\mathrm{Na}^{+}, \mathrm{K}^{+}, \mathrm{Ca}^{2+}$, and $\mathrm{Mg}^{2+}, \mathrm{HSO}_{4}{ }^{-}$, and $\mathrm{SO}_{4}{ }^{2-}$, respectively. The total dissolved solids (TDS) are approximately $2100 \mathrm{mg} / \mathrm{L}$. Option 3 uses sulfuric acid at $1 \mathrm{wt} \%$ heated to $90{ }^{\circ} \mathrm{C}$. Approximately one third of the hot, salt-containing water is evaporated to reduce the volume of brine that requires disposal. The ions in the brine are the same as in option 2 with a slightly greater TDS of approximately $2500 \mathrm{mg} / \mathrm{L}$. In general, the costs of brine disposal vary widely, depending upon the TDS content. Brine with high levels of organic salts must be disposed of, for example, using a combination of filtration technologies and possibly deep-well injection to dispose of concentrate from the filtration processes. For example, the City of Morro Bay desalination facility has been reported to treat desalinate saltwater with TDS of approximately $3500 \mathrm{mg} / \mathrm{L}$ at a cost of approximately $\$ 1.14 / \mathrm{m}^{3}$ [29]. In contrast, the Carmel Area Wastewater district (CAWD) desalination treatment facility, which treats municipal wastewater for irrigation purposes, has a reported cost of $\$ 1.70 / \mathrm{m}^{3}$ [29]. Deep-well injection is significantly more expensive with a reported cost of approximately $\$ 6.30 / \mathrm{m}^{3}$ ( $\$ 1 / \mathrm{barrel}$ ). For the purposes of estimating the cost of water filtration, a value of $\$ 1.70 / \mathrm{m}^{3}$ is employed with lower and upper bounds of $\$ 1.14$ and $\$ 3.40 / \mathrm{m}^{3}$, respectively, assumed for the sensitivity analysis. For comparison, the cost for wastewater treatment has 
Table 5 Breakdown of operating cost components for leaching process at $22.68 \mathrm{dt} / \mathrm{h}$ and also total processing cost, including capital costs for three options

\begin{tabular}{|c|c|c|c|c|c|}
\hline \multirow[t]{2}{*}{ Cost component } & \multirow[t]{2}{*}{ Usage } & \multirow[t]{2}{*}{ Unit cost } & \multicolumn{3}{|c|}{$\operatorname{Cost}(\$ / \mathrm{dt})$} \\
\hline & & & Option 1 & Option 2 & Option 3 \\
\hline Salaries & $45 \%$ & $\$ 52,700$ & $\$ 0.66$ & $\$ 0.66$ & $\$ 0.66$ \\
\hline Steam in evaporator & 30.4 MMBTU/h & $\$ 9 / \mathrm{MMBTU}$ & 0 & 0 & 12.06 \\
\hline Natural gas in dryer & 34.6 MMBTU/h & $\$ 5 / \mathrm{MMBTU}$ & 7.63 & 7.63 & 7.63 \\
\hline Electricity for pumps & $67 \mathrm{HP}$ & $\$ 0.10 / \mathrm{kWh}$ & 0.22 & 0.22 & 0.22 \\
\hline Sulfuric acid & $98 \mathrm{wt} \%$ & $\$ 400 /$ ton & 0 & 0.44 & 4.42 \\
\hline \multicolumn{6}{|l|}{ Brine disposal } \\
\hline All options & $62-68,000 \mathrm{lb} . / \mathrm{h}$ & $\$ 1.70 / \mathrm{m}^{3}$ & 2.11 & 2.34 & 2.30 \\
\hline Yield loss & $0-10 \%$ & $\$ 66 / \mathrm{dt}$ & 0 & 3.30 & 6.60 \\
\hline Other fixed costs & $100 \%$ & $\$ 225,000 / \mathrm{yr}$ & 1.26 & 1.26 & 1.26 \\
\hline \multicolumn{3}{|l|}{ Total operating cost } & 11.88 & 15.85 & 35.15 \\
\hline \multicolumn{3}{|c|}{ Total process cost (sum of operating and capital costs) } & 12.68 & 16.65 & 36.03 \\
\hline
\end{tabular}

Yield losses for options 1,2, and 3 are assumed to be 1, 5, and $10 \%$, respectively. Options 1, 2, and 3 are water at $24{ }^{\circ} \mathrm{C}, 0.1 \%$ acid at $24{ }^{\circ} \mathrm{C}$, and $1 \%$ acid at $90{ }^{\circ} \mathrm{C}$, respectively been reported as $\$ 0.53 / \mathrm{m}^{3}$ in the bioprocess industry [30]. The TDS levels of the brine water from leaching are not high compared to other chemical processes, so those values may apply. For example, the EPA standard for TDS in drinking water is $500 \mathrm{mg} / \mathrm{L}$ [31], while the TDS in potato processing wastewater is about $29,000 \mathrm{mg} / \mathrm{L}$ [32].

Experiments demonstrate that the loss of organic material during the leaching operation increases with the severity of the operation (Idaho National Laboratory, unpublished results). For this work, the losses of organic material (yield loss) for options 1,2 , and 3 were assumed to be 1,5 , and $10 \%$, respectively, at a cost of $\$ 66 / \mathrm{dt}$ of lost organic material. The cost of disposing of the lost material is not considered separately because those costs are expected to be small compared to the yield loss of $\$ 66 / \mathrm{dt}$. The yield/disposal loss assumed here is conservative because the soluble organics lost at room temperature and $0.1 \%$ acid will be primarily small molecular weight extractables, which are converted into undesirable non-condensible gases during thermochemical conversion. Similar to the air classification process, the number of operators is estimated using Eq. (1) by considering that 12 new operations are added (three leachers, a drainer, a water recycle, four condensers, an evaporator, a brine heater, and a dryer), such that $45 \%$ of a full-time operator $(18 \mathrm{~h} /$ week $)$ is needed to operate the acid leaching system. We note that the authors have experience operating a continuous-feed pilot-scale chemical treatment system, and the labor estimate above is within the expected range based upon our experience. Other leaching operating costs are summarized in Table 5, which shows that the total operating costs for options 1,2 , and 3 are estimated to be $\$ 11.88, \$ 16.65$, and $\$ 36.03 / \mathrm{dt}$ of wood chips, respectively.

As indicated in Supplementary Fig. 1, options 2 and 3 achieve similar levels of extraction of inorganics that are both substantially better than option 1 . The total process cost of options 2 and 3 are approximately 30 and $184 \%$ higher than option 1, respectively. Consequently, option 2 is chosen as the base method for biomass leaching. For option 2, the heating cost to dry the final products to $8 \%$ water content wet basis comprises nearly $50 \%$ of the total operating costs, indicating that reducing heating costs is important to decrease the total operating cost. Furthermore, for option 2, approximately $95 \%$ of the total process cost is operating cost, so that capital cost is relatively less important. The relatively high costs associated with leaching emphasize the importance of employing air classification or a similar separation method to isolate fractions of biomass that have highly concentrated inorganics content, so that the entire stream of biomass does not need to be leached and subsequently dried.

\section{Results and Discussion}

\section{Process Cost for Combined Air Classification and Leaching}

The costs associated with combined air classification/ leaching process are illustrated using an example. A VFD frequency of $12 \mathrm{~Hz}$ was selected for air classification because of its relatively high removal of inorganics and relatively low loss of organics as shown in Table 3 . The biomass fraction separated at $12 \mathrm{~Hz}$ is subsequently leached using $0.1 \mathrm{wt} \%$ sulfuric acid at $24{ }^{\circ} \mathrm{C}$. Air classification isolates a fraction of wood chips at $2.07 \mathrm{dt} / \mathrm{h}$ (9.1\% of the total feedstock flow rate) that has high ash content. The high ash fraction is subsequently leached and dried to $8 \%$ water content for an approximate cost of $\$ 16.65 / \mathrm{dt}$, as listed in Table 5 , which corresponds to 
$\$ 34.43 / \mathrm{h}$ at a scale of $2.07 \mathrm{dt} / \mathrm{h}$. The actual leaching cost per dry ton of leached product would likely be slightly higher because of the smaller scale $(2.07 \mathrm{dt} / \mathrm{h}$ compared to $22.68 \mathrm{dt} / \mathrm{h}$ ) and the loss of economies of scale; however, the cost of leaching is not strongly dependent upon scale because operating costs, which increase approximately linearly with process scale, comprise approximately $95 \%$ of the total processing cost. Assuming $5 \%$ loss of solid material during leaching, an equivalent to $1.96 \mathrm{dt} / \mathrm{h}$ of material is recovered from the leacher, and this material is then mixed back in with the low-ash fraction from the air classification to create a final product stream at 22.58 $\mathrm{dt} / \mathrm{h}$. The combined process cost is $22.68 \times 0.83+34.43 /$ $22.58=\$ 2.36 / \mathrm{dt}$ of product material.

Figure 1 displays the estimated total process costs and the removal rates of key feedstock components for the asreceived materials and six other possible scenarios. For the as-received materials, the organic losses and the processing costs, as well as the removal rates of $\mathrm{SiO}_{2}$, total ash, and the combined oxides of $\mathrm{K}, \mathrm{Ca}, \mathrm{Mg}, \mathrm{Na}$, and $\mathrm{P}$ $(\mathrm{AAEMS}+\mathrm{P})$ are all assumed to be zero. For the second and third scenarios, $(\varnothing \leq 10 \mathrm{~Hz}$ and $\varnothing \leq 15 \mathrm{~Hz}$, respectively), the material collected using VFD frequencies of 10 and $15 \mathrm{~Hz}$ (rows 2 and 4 in Table 3) is discarded or repurposed as described above. The solid and hollow squares show the estimated costs assuming that the cost associated with yield loss during air classification are $\$ 20$ and $\$ 40 / \mathrm{dt}$, respectively, for repurposed organic material. Note that the removed fractions have high ash content, and for the purposes of this simulation, "yield losses" are assumed to accrue only for repurposed organic material. Scenarios 2 and 3 demonstrate that higher VFD frequencies and fan speeds reduce silica, total ash, and AAEMs + P content of the passing fraction; however, increasing levels of organic material are also removed, which incurs greater yield losses. At a VFD frequency of $15 \mathrm{~Hz}, 12 \%$ of the organic material is removed in the high-ash fraction, which also removes $56 \%$ of total ash and $28 \%$ of AAEMs + P for a total estimated cost of $\$ 3.78 / \mathrm{dt}$ of product, assuming a yield loss of $\$ 20 / \mathrm{dt}$ for repurposed organic material. Note that yield losses comprise the majority of the process cost as evidenced by the fact that assuming a higher yield loss of $\$ 40 / \mathrm{dt}$ for repurposed organic material increases the estimated process cost by nearly double. Scenario $4(\mathrm{~L} \leq 15 \mathrm{~Hz})$ shows the impact on cost and the key metrics if the high-ash fraction from scenario 3 is leached instead of repurposed. The total processing cost decreases to approximately $\$ 3.08 / \mathrm{dt}$ of product material and is nearly independent of the cost associated with yield loss because the loss of organic material is very low. A consequence of leaching the high-ash fraction, however, is that substantially less silica and total ash are removed from the process stream
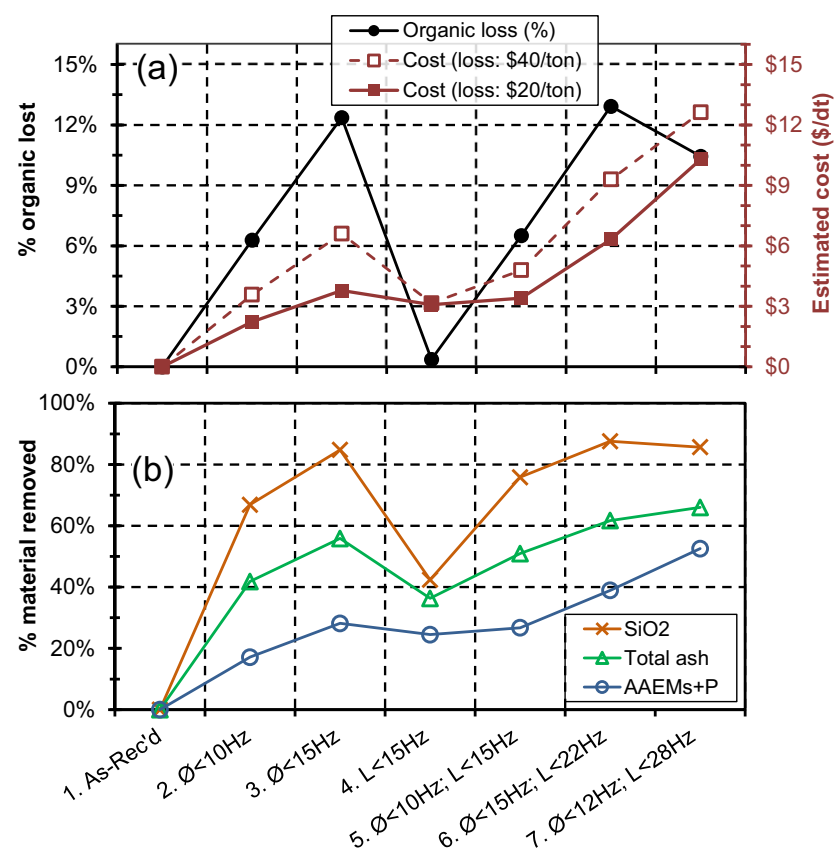

Fig. 1 Effectiveness and estimated costs of several scenarios to reduce the inorganic content using combinations of air classification and leaching

because leaching is less effective at removing silica than it is at removing AAEMs (Idaho National Laboratory, unpublished results).

Scenarios 5, 6, and 7 in Fig. 1 illustrate possibilities to use air classification to create three material fractions that can either be repurposed, leached, or passed without further preprocessing in order to maximize the removal of total ash and AAEMS $+\mathrm{P}$ while minimizing process cost. In scenario $5(\varnothing \leq 10 \mathrm{~Hz}, \mathrm{~L} \leq 15 \mathrm{~Hz})$, air classification is first performed using a VFD frequency of $15 \mathrm{~Hz}$, and the separated material is subsequently air classified again at $10 \mathrm{~Hz}$ to produce a total of three fractions. The lightest fraction is repurposed, the intermediate fraction is leached, and the heaviest fraction is passed without further preprocessing. Note that although scenarios 5-7 employ two air classification operations, the cost of air classification is not increased significantly because the volume of material in the second operation is very low and can likely use exhaust air from the first operation with minimal modification to the equipment. Scenarios 6 and 7 follow the same general operations as scenario 5 but use higher VFD frequencies to separate greater amounts of inorganic and organic material. For scenario 7 $(\varnothing \leq 12 \mathrm{~Hz}, \mathrm{~L} \leq 28 \mathrm{~Hz}$ ), the material separated with a VFD of $12 \mathrm{~Hz}$ is repurposed, while the remaining material separated with a VFD of $28 \mathrm{~Hz}$ is leached. The combined process cost, including yield losses, is in the range of $\$ 10-12 / \mathrm{dt}$ of product material and results in a removal of $11,66,53$, and $86 \%$ of organics, total ash (inorganics), 
AAEMS + P, and silicon, respectively. An important conclusion from the data in Fig. 1 is that a combination of air classification and leaching can be more economical than air classification alone, depending upon the costs associated with yield losses and also the inorganic species that are targeted for removal.

The value proposition of using air classification, chemical leaching, or a combination of both ash removal technologies will depend upon the cost impacts of the ash species on specific biofuel conversion processes, including impacts on yield, catalyst deactivation and poisoning, and reactor fouling, as well as intermediate and final fuel qualities. An important consideration is that as demand for feedstock material increases, the unit cost (i.e., grower payment) of the material also increases. For example, the Billion Ton Update projects that as much as 36 million dry metric tons of biofuels resources may be available in 2022 for a mean price of approximately $\$ 55 / \mathrm{dt}$ (DOE, 2011). Increasing the demand to 182 million dry tons results in an increased projected mean price of approximately \$66/dt. Interpolating inside the supply demand curve indicates that increasing demand by $10 \%$ to replace material that is removed by an air separation process to reduce the ash content results in a mean price increase of all the resource biomass by approximately $\$ 1.4 / \mathrm{dt}$. Of course, actual monetary values will vary according to location and other factors. The point is that using chemical leaching to reduce organic losses associated with air classification reduces the demand for new material and thereby assists in reducing feedstock costs. Although this supply/demand effect is real and may be significant at high feedstock volumes, the impacts are not included in the analysis above, which focuses only on material processing costs.

\section{Conclusions}

The capital and operating costs of combined air classification and leaching of loblolly pine logging residues to remove inorganic species were analyzed and found to be promising preprocessing technologies to prepare logging residues for thermochemical conversion. In an example scenario (no. 6 discussed above), for a biomass flow rate of $22.68 \mathrm{dt} / \mathrm{h}$, the combined process cost, including air classification and chemical leaching, is in the range of $\$ 6-9 / \mathrm{dt}$ of product material and results in removals of $14,62,39$, and $88 \%$ of organics, total ash (total inorganics), alkaline earth metals and phosphorus $(\mathrm{AEMS}+\mathrm{P})$, and silicon, respectively. In another scenario that involves leaching a greater amount of material (no. 7 discussed above), the combined process cost, including yield losses, is in the range of $\$ 10-12 / \mathrm{dt}$ of product material and results in a removal of $11,66,53$, and $86 \%$ of organics, total ash, AEMS + P, and silicon, respectively. Comparing these scenarios indicates that leaching material rather than discarding it tends to reduce the loss of organics but also fails to remove as much AEMS $+\mathrm{P}$. The effects of key parameters are analyzed and indicate that costs associated with loss of organic material from air classification and leaching (yield losses), brine disposal, and labor have the greatest potential to impact the total processing cost.

Acknowledgments This work is supported by the US Department of Energy under Department of Energy Idaho Operations Office Contract No. DE-AC07-05ID14517. The US government and the publisher, by accepting the article for publication, acknowledges that the US government retains a non-exclusive, paid-up, irrevocable, worldwide license to publish or reproduce the published form of this manuscript, or allow others to do so, for US Government purposes. The authors have no other relevant affiliations or financial involvement with any organization or entity with a financial interest in or financial conflict with the subject matter or materials discussed in the manuscript apart from those disclosed. No writing assistance was utilized in the production of this manuscript.

Open Access This article is distributed under the terms of the Creative Commons Attribution 4.0 International License (http:// creativecommons.org/licenses/by/4.0/), which permits unrestricted use, distribution, and reproduction in any medium, provided you give appropriate credit to the original author(s) and the source, provide a link to the Creative Commons license, and indicate if changes were made.

\section{References}

1. U.S. Dept. of Energy. Jones SB, Meyer PA, Snowden-Swan LJ, Padmaperuma A, Tan ECD, Dutta A, Jacobson JJ, Cafferty KG (Leads) (2013). Economics for the conversion of lignocellulosic biomass to hydrocarbon fuels. Fast pyrolysis and hydrotreating bio-oil pathway. Pacific Northwest National Laboratory. PNNL23053.

2. U.S. Dept. of Energy (2013) Logistics, costs, and GHG impacts of utility-scale cofiring with $20 \%$ biomass, Idaho National Laboratory, Pacific Northwest National Laboratory, Technical Report INL/EXT-12-25252 and PNNL-23492.

3. U.S. Dept. of Energy. Langholtz MH, Stokes BJ, Eaton LM (Leads), (2016) Billion-Ton Report: advancing domestic resources for a thriving bioeconomy, Volume 1: Economic Availability of Feedstocks. ORNL/TM-2016/160. Oak Ridge National Laboratory, Oak Ridge, TN. 448p.

4. Fahmi R, Bridgwater A, Donnison I, Yates N, Jones JM (2008) The effect of lignin and inorganic species in biomass on pyrolysis oil yields, quality and stability. Fuel 87(7):1230-1240. doi:10.1016/j. apenergy.2015.03.034

5. Patwardhan PR, Satrio JA, Brown RC, Shanks BH (2010) Influence of inorganic salts on the primary pyrolysis products of cellulose. Bioresour Technol 101(12):4646-4655. doi:10.1016/j. biortech.2010.01.112

6. Wang K, Zhang J, Shanks BH, Brown RC (2015) The deleterious effect of inorganic salts on hydrocarbon yields from catalytic fast pyrolysis of lignocellulosic biomass and its mitigation. Appl Energy 148:115-120. doi:10.1016/j.fuel.2007.07.026

7. Jenkins BM, Baxter LL, Miles TR, Miles TR (1998) Combustion properties of biomass. Fuel Process Technol 54(1-3):17-46. doi:10.1016/S0378-3820(97)00059-3 
8. van Loo S, Koppejan J (2010) The handbook of biomass combustion and co-firing. Routledge, Oxford, UK

9. Weiss ND, Farmer JD, Schell DJ (2010) Impact of corn Stover composition on hemicellulose conversion during dilute acid pretreatment and enzymatic cellulose digestibility of the pretreated solids. Bioresour Technol 101(2):674-678. doi:10.1016/j. biortech.2009.08.082

10. Lacey JA, Aston JE, Westover TL, Cherry RS, Thompson DN (2015) Removal of introduced inorganic content from chipped forest residues via air classification. Fuel 16:265-273. doi:10.1016/j. fuel.2015.07.100

11. Liu X, Bi XT (2011) Removal of inorganic constituents from pine barks and switchgrass. Fuel Process Technol 92:1273-1279. doi:10.1016/j.fuproc.2011.01.016

12. Klumpar IV, Currier FN, Ring TA (1986) Air classifiers. Chemical Engineering 93(5):77-92

13. J rgensen U, Sander B (1997) Biomass requirements for power production: how to optimize the quality by agricultural management. Biomass Bioenergy 12(3):145-147. doi:10.1016/S09619534(97)00001-9

14. Davidsson KO, Korsgren JG, Pettersson JBC, Jäglid U (2002) The effects of fuel washing techniques on alkali release from biomass. Fuel 81(2):137-142. doi:10.1016/S0016-2361(01)00132-6

15. Jenkins BM, Bakker RR, Wei JB (1996) On the properties of washed straw. Biomass Bioenergy 10:177-200. doi:10.1016 /0961-9534(95)00058-5

16. Turn SQ, Kinoshita CM, Ishimura DM (1997) Removal of inorganic constituents of biomass feedstocks by mechanical dewatering and leaching. Biomass Bioenergy 12:241-252. doi:10.1016 /S0961-9534(97)00005-6

17. Said N, Bishara T, García-Maraver A, Zamorano M (2013) Effect of water washing on the thermal behavior of rice straw. Waste Manag 33:2250-2256. doi:10.1016/j.wasman.2013.07.019

18. Suzuki T, Deguchi K, Kimura Y, Funaki M, Yamada T (1999) Hydrogasification of wood for high heating-value gas production $\mathrm{X}$ : effect of pretreatment of Japanese oak bark by $\mathrm{HNO} 3$ oxidation on subsequent iron-catalyzed hydrogasification. J Wood Sci 45(1): 76-83. doi:10.1007/BF00579527

19. Mourant D, Wang Z, He M, Wang XS, Garcia-Perez M, Ling K, Li CZ (2011) Mallee wood fast pyrolysis: effects of alkali and alkaline earth metallic species on the yield and composition of bio-oil. Fuel 90:2915-2922. doi:10.1016/j.fuel.2011.04.033

20. Scott DS, Paterson L, Piskorz J, Radlein D (2001) Pretreatment of poplar wood for fast pyrolysis: rate of cation removal. J Anal Appl Pyrol 57:169-176. doi:10.1016/S0165-2370(00)00108-X
21. Dobele G, Dizhbite T, Rossinskaja G, Telysheva G, Meier D, Radtke S, Faix O (2003) Pre-treatment of biomass with phosphoric acid prior to fast pyrolysis: a promising method for obtaining 1,6anhydrosaccharides in high yields. J Anal Appl Pyrol:68-69. doi:10.1016/S0165-2370(03)00063-9

22. Reza MT, Emerson R, Uddin MH, Gresham G, Coronella CJ (2015) Ash reduction of corn Stover by mild hydrothermal preprocessing. Biomass Conv Bioref 5:21-31. doi:10.1007/s13399-0140122-x

23. U.S. Dept. of Energy (2014) Feedstock supply system design and analysis. Idaho National Laboratory. INL-EXT-33227.

24. Carpenter D, Westover T, Jablonski W, Czernik S (2014) Biomass feedstocks for renewable fuel production: a review of the impacts of feedstock and pretreatment on the yield and product distribution of fast pyrolysis bio-oils and vapors. Green Chem 16(2):384-406. doi:10.1039/C3GC41631C

25. Saltberg A, Brelid H, Theliander H (2006a) Removal of metal ions from wood chips during acidic leaching 1: comparison between Scandinavian softwood, birch and eucalyptus. Nordic Pulp Paper Res J 21:507-512

26. Bejan A (1993) Heat transfer. John Wiley, New York, pp. 167-170

27. KLM Technology Group (2014) General process plant cost estimating ( engineering design guideline). Available at http://kolmetz.

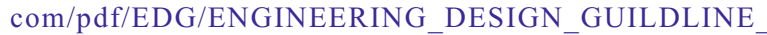
General_Plant_Cost_Estimating_Rev01web.pdf. Accessed Sept. 6, 2016.

28. Peters MS, Timmerhaus KD, West RE (2003) Plant design and economics for chemical engineers, 5th ed. McGraw Hill, New York, p242.

29. Hemping A, Economic analysis of reverse osmosis desalination of water for agricultural irrigation applications, California Polytechnic State University, San Luis Obispo, CA. March 2011. Available at http://digitalcommons.calpoly.edu/cgi/viewcontent.cgi?article $=1021 \&$ context $=$ braesp. Accessed Feb. 18, 2016.

30. Heinzle E, Biwer AP, Cooney CL (2007) Development of sustainable bioprocesses: modeling and assessment. John Wiley and Sons, London, UK, p. 91

31. EPA secondary drinking water regulations: guidance for nuisance chemicals. http://water.epa.gov/drink/contaminants/secondarystandards. cfm. Accessed July 2015.

32. Wang LK, Hung YT, Lo HH, Yapijakis C (2006) Waste treatment in the food processing industry. CRC Press, Taylor \& Francis, Boca Raton, p. 209 